\title{
Can a Good Performance Management Technique Improve Public Health Outcome? A Rapid Assessment of Public Health Organization in Nigeria
}

\author{
David Akpan \\ LIGS University, Honolulu, HI, USA \\ Email: davesunny23@gmail.com
}

How to cite this paper: Akpan, D. (2019) Can a Good Performance Management Technique Improve Public Health Outcome? A Rapid Assessment of Public Health Organization in Nigeria. Journal of Human Resource and Sustainability Studies, 7, 121-136.

https://doi.org/10.4236/jhrss.2019.72009

Received: February 22, 2019

Accepted: March 30, 2019

Published: April 2, 2019

Copyright $\odot 2019$ by author(s) and Scientific Research Publishing Inc. This work is licensed under the Creative Commons Attribution International License (CC BY 4.0). http://creativecommons.org/licenses/by/4.0/

\section{Open Access}

\begin{abstract}
Performance management practice dates back as one of the critical parts of the human resource management process of any organization which is expected to help the organization make policy level decisions, and program direction and improve to organizational learning. A few organizations have made an attempt to institute a performance management system to assist with assessing work productivity, with findings not used to compare with agreed goal of the organization. Relatively, if the focus of the organization is to deliver public health outcomes, how is performance management a significant step to help the organization shapes its workforce productivity towards achieving on its public health outcomes? What system is in place to enable the performance management process to have a direct impact on public health outcome? This work intends to determine the capacity of public health organizations performance management system in driving work productivity leading to achievement of established public health outcome. A quantitative assessment was conducted using a Performance Management Self-Assessment Tool (PMSAT) developed by Turning Point Performance Management National Excellence Collaborative in 2004 and data collected were analyzed using a statistical tool. The results of the findings revealed a high-level commitment from the leadership, alignment of performance priority areas to the Agency's mission and the ability of the performance system to measure key areas like health status of personnel, human resource development, financial systems and management practices. However, the current system lacks the capacity to develop its Information and Data System to provide timely reports on performance outcome as well as providing feedback for program and management decision and relationship with clients and stakeholders. In con-
\end{abstract}


clusion, it is important to mention that performance management is more than just a process for rewarding employee's productivity but a tool that helps organizations measure their overall performance based on its employee's efforts.

\section{Keywords}

Employee's Productivity, Human Resource Management, Modern Performance Management Practice, Organizational Learning and Performance, Performance Discussion and Appraisal, Performance Management, Performance Management Self-Assessment Tool, Performance Management System, Public Health Outcomes, Traditional Performance Management Practice

\section{Introduction}

Performance management has in several times been reduced to a tool or process of monitoring individuals. Reasons for performance appraisal include a measure that provides justifications for professional or career development, accountability, recognition, promotion, compensation, discipline and increase in remuneration [1]. Can this be a narrow thinking of performance management? Performance management should be more of a system that helps organization improves in their mandate to deliver their vision. Reason is that individuals who are part of the organizations were recruited to work towards achieving the organization's vision and mandate. Limiting performance appraisal to specific areas may only create a narrow pathway for the organization [2]. The outcome of performance appraisal should assist the organization to identify areas of strong and weak performance in relation to its staff, system and processes as provided by the aggregated analysis obtained from individual performance appraisal forms [3].

Invariably, performance management for public health outcome is considered to human's effort towards reduction in morbidity while improving health and wellbeing of all population. In order to achieve this outcome, prominent organizations have decided to invest in designing and implementing interventions that gear towards achieving improving their performance management system. These levels of investment for most organizations are worth the value of their existence, and contributions to social change and become a trademark for global recognition.

Interestingly, in order to maintain the level of value for productivity and credibility, these organizations define processes and systems that allow for recruitment of talented and passionate individuals to work towards achieving the organization's set vision. The internal talent management process also ensures that individuals hired to deliver on their job roles are productive and very rewarding to the organization. This therefore becomes an aspect of human resource man- 
agement that is described as "performance management". Performance management thus is a process by which managers and employees work together to plan, monitor and review an employee's work objectives and overall contribution to the organization [4]. What is significant with performance management is the measure of productivity.

This therefore brings to mind the question of whether every performance management system leads to improve work productivity. Relatively, if the focus of the organization is to deliver public health outcomes, how is performance management a significant step to help the organization shapes its workforce productivity towards delivering on its public health outcomes? What system is in place to enable the performance management process to have a direct impact on public health outcome? These are questions this work will attempt to answer using 6 public health organizations in Nigeria as a case study.

This study will further establish the missing link and relationship between performance management and public health outcomes. This work intends to conduct a rapid assessment of Performance Management System of these organizations to determine its capacity to drive work productivity leading to achievement of established public health outcome. The findings from the assessment will be analyzed to inform improvement in the organization's performance management process. The outcome of the assessment will be of great benefit to the participating organizations in reforming their system in line with the gap analysis. The study will also build new body of knowledge for further research on how performance management system can help organizations deliver on its set mandate in health, education and/or social service sector(s).

\section{Evaluating the Problem and Rationale}

\subsection{Problem Statement}

Performance management practices can date back as one of the critical part of the human resource management process of any organization. The process of performance management spanned through three steps-work analysis, appraisal and post reviews [5]. The first process provides opportunity for the employee to understand, set and aligns its performance objectives with the organization's goal. The next step will then focus on appraising the employee at the end of the year on his/her performance vis-à-vis the performance objectives. The last step therefore which seems to be less practiced centers around a post review of all performance appraisal and draws inference on whether the outcome can reflect the measure of success for the organization. Worthy of note is that every organization has its annual strategic or operational goal. It is the effort of the various individuals in the organization that can show whether the strategic or operational goal has been achieved or not.

Several times, organizations tend to measure the rate of success using a process of reviewing their strategic or operational plans [6]. This may sound as a double standard process or more of a programmatic review than a management 
approach to measuring organizational performance. Organizational performance goes beyond implementation of activities on workplan. Remember, there are staff that are in the operations, finance, logistics, travel, security, fleets, communication, etc. who do not have direct bearings on the activities in the field with beneficiaries. However, their daily work assignment has a significant way of influencing the performance of the organization. It is therefore important to adopt a management approach to measuring organizational performance using the performance management system.

Although, a few organizations have made an attempt to institute a performance management system to assist with assessing work productivity, such findings are not used to compare with agreed goal of the organization [7]. This is practiced as a continuous or routine review of the employee's deliverables in comparison with agreed expectations. The outcome is now more of a routine and monotony than a productive process in most organizations [8]. This has further led to several abuses of the performance management process being used as a system to reward or discipline instead of a measure of a cumulative outlook of the organization's wellbeing. Performance management is supposed to help organization deduce how the general performance of their workforce affects the vision of the organization within the stipulated period.

Several studies have been conducted more around how performance appraisal or management can improve employee's motivation or productivity [9] [10]. The study findings show the effect of performance appraisal on increasing motivation and job satisfaction, which in turn influences work productivity. The study looks more at the process than a system that will help the organization measure overall performance as a result of the performance review and appraisal process. This becomes the central consideration of this work in looking at a system approach to performance management and its impact on the organization's performance (public health outcome).

\subsection{Objectives}

The primary objective of this rapid assessment is to establish relationship between performance management and public health outcome. Specifically, the work will:

1) assess system gaps in Performance Management System in public health organization in Nigeria.

2) propose model and innovations to strengthen performance management for public health productivity.

\section{Methodology and Process of Analysis}

The study method selected for this work was a qualitative approach with a mix of quantitative desk research. The desk research basically focuses on collecting secondary data on how organizations use performance management data to improve their development. The quantitative assessment used a Performance Man- 
agement Self-Assessment Tool (PMSAT) developed by Turning Point Performance Management National Excellence Collaborative in 2004. The assessment tool helped the researcher in identifying the extent to which the components of the performance management systems are strong to deliver health outcomes. The model as developed recognizes four (4) components of performance management system to include-performance standards, performance measurement, reporting of progress and quality (or performance) improvement process (Figure 1).

For each component, several questions serve as indicators of measuring performance management capacity. These questions cover elements of the capacity such as having the necessary resources, skills, accountability, and communications to be effective in each component. A total of forty-four (44) indicative questions are structured across the five sections of the tool. The tool uses a 3-point Likert scale patterns namely 1) "No"; 2) "Somewhat"; and 3) "Yes (fully functional)".

Performance Management Self-Assessment Tool is structured as reflected in Table 1:

The tool was administered as paper-based and data collected analyzed using statistical software.

\section{Presentation of Findings from Rapid Assessment}

\subsection{Organization's Characteristics}

Table 1 reveals characteristics of the organizations assessed from this study. Major characteristics assessed were related to their existence from year of establishment, experience in project management as well as related experience of their project managers (Table 2 ).

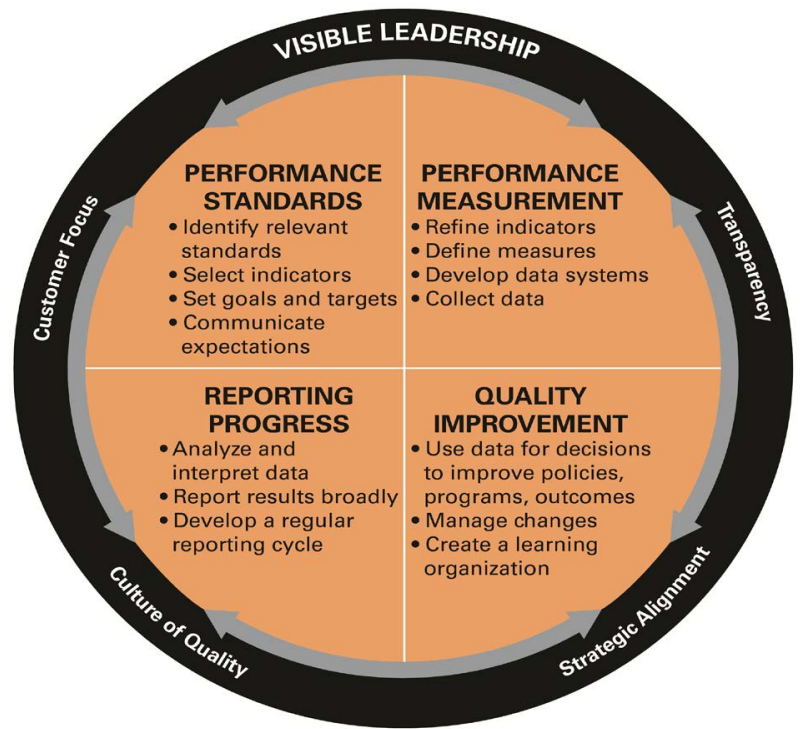

Figure 1. Components of Performance management (Source: Turning Point. From Silos to Systems: Using Performance Management to Improve the Public's Health, 2003). 
Table 1. Summary structure of the performance management self-assessment tool (Source: Turning Point Performance Management National Excellence Collaborative, 2004).

\section{Standards}

Overall readiness and accountability.

Performance standards-assesses the establishment of organizational or system performance standards, targets, and goals to improve public health practices.

Performance measures - evaluates the development, application, and use of performance measures to assess achievement of such standards.

Reporting of progress-assesses the documentation and reporting of progress in meeting standards and targets and sharing of such information through feedback.

Quality improvement-evaluates the establishment of a program or process to manage change and achieve quality improvement in public health policies, programs or infrastructure based on performance standards, measurements, and reports.
\# of indicative assessment questions

12 questions

9 questions

6 questions

8 questions

9 questions

Table 2. Characteristics of Organizations disaggregated by their project management experience.

\begin{tabular}{ccc}
\hline Characteristics & N & $\%$ \\
\hline & Organization's History/Existence & \\
Less than 12 years & 13 & 59.1 \\
More than 12 years & 9 & 39.9 \\
& Project Management Experience & \\
Not Provided & 11 & 50.0 \\
Less than 6 years & 8 & 37.5 \\
More than 6 years & 3 & 12.5 \\
Highest Education Qualification of Project Managers & \\
Bachelor Degree & 16 & 72.7 \\
Post Graduate Degree & 4 & 18.2 \\
Below First Degree & 2 & 9.1 \\
\hline
\end{tabular}

Source: Field survey, 2018.

Result of the data analysis shows in Table 2 reveals that most of the organisations 59.1\% were established before 2006 about 12 years ago, while three organisations were established in 2003, 2006 and 2014 respectively. Fifty percent of the organisations studied did not mention the number of projects executed since its establishment, either because the projects are still ongoing and or they did not carry out any projects. Out of this $50 \%$ that reported the number of projects executed, 8 organisations have executed less than 6 projects since its establishment, while very few organisations have executed $6-10$ projects and more than 10 projects respectively with an average staff strength of 11 in previous projects and 
13 in current/ongoing projects. The organisations studied have executed projects in at least 6 communities. Most of the project managers $16(72.7 \%)$ have bachelor's degree as their highest educational qualification while $4(18.2 \%)$ have post graduate degree as their highest educational qualification.

\subsection{Descriptive Analysis by Performance Management Domains}

This section focuses on the presentation of the findings following the analysis of rapid assessment. The presentation is done using a Sunburst Chart (Pie chart) identifying key areas of strength and weakness in the organization's Performance Management System, as its readiness towards measuring public health outcomes.

\subsubsection{Overall Readiness and Accountability}

This section of the rapid tool assessed the readiness and accountability of the organization's leadership towards building or strengthening an effective performance management system.

Findings from Figure 2 reveal that $53 \%$ of processes to enable a functional Performance Management System were fully operational. This is indicated in a show of high-level commitment from the leadership, alignment of performance priority areas to the organization's mission and the ability of the performance system to measure key areas like health status of personnel, human resource development, financial systems and management practices. Other areas of strengths are that the mangers are held accountable for developing, maintaining, and improving the performance management system as well as the Agency's commitment to provide incentives for performance improvement. It also depicts that the leaders within the agency has developed a culture for performance and have dedicated staff and financial resources assigned to performance management functions.

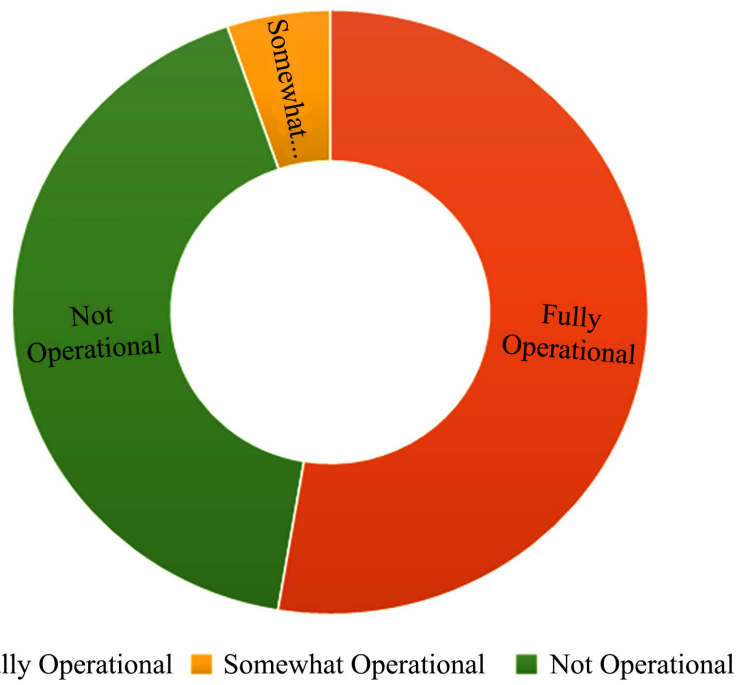

Figure 2. Chart showing results of analysis on overall readiness and accountability of Performance Management System (Source: Data Analysis). 
However, amidst the key strengths are several other weaknesses in Performance Management systems that rates the organizations at $42 \%$ based on the rapid assessment outcome. Interestingly, the current performance management system does not commit to developing capacity of its human resource and workforce on performance development around the core competencies. The system lacks the capacity to develop its Information and Data System provides timely reports on performance outcome as well as provides feedback for program and management decision and relationship with clients and stakeholders.

There is also a gap in how the system links performance with service delivery outcomes and providing sufficient details for integrating performance management effort in service delivery outcomes. This could be based on the fact that managers are not trained on Performance management as spotted in the assessment and having a process or mechanism to align the various components of the organizations with the performance management system and its strategic plan.

\subsubsection{Performance Standards}

This section measures Organization's Performance Management System as it pertains to setting up standard for measuring performance (Figure 3).

The analysis pictured above revealed that organization's processes of setting standards for performance management is partially operational rated at $50 \%$. Key areas considered as strengths include developing performance standards for achieving annual targets which aligns with activities and managers with employees are held accountable to meeting the standards and target. Similarly, the process of developing standards is defined and at most times participatory. The assessment also revealed that staffs are not trained to use performance standards, accept communications from Human Resources at orientation and during performance appraisal period.

The critical gaps identified from the assessment are that the performance standards are not clearly aligned with leading health indicators as defined by the Federal Government. In other words, the standards set for performance are not geared towards contributing to the National health targets. Similarly, the performance benchmarks do not account for cumulative results that allow the organizations to compare its contribution to the National target vis-à-vis other organizations. There are also no clearly defined processes of ensuring that staff objectively defined targets consider contributing to the National health target or benchmarks. There is also a gap in ensuring that staffs are acquainted on performance standards and their contributions to the Agency's goal as well as National health targets.

\subsubsection{Performance Measurement}

This section of the rapid assessment reflected on the process and structure of performance measurement and how the method of performance measurement helps these organizations to align the outcome of its performance reviews with public health outcomes (Figure 4). 


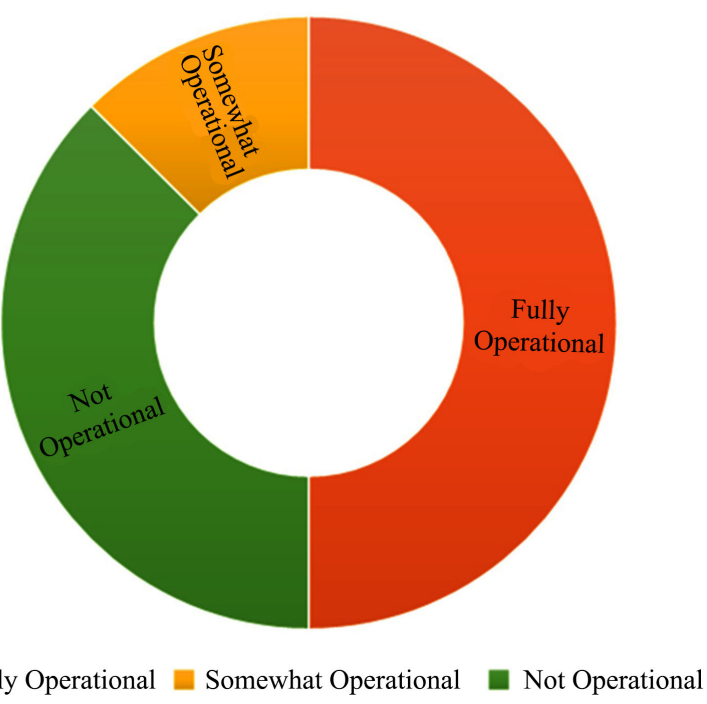

Figure 3. Chart showing results of analysis on the Process for Establishing Performance Standards (Source: Data Analysis).

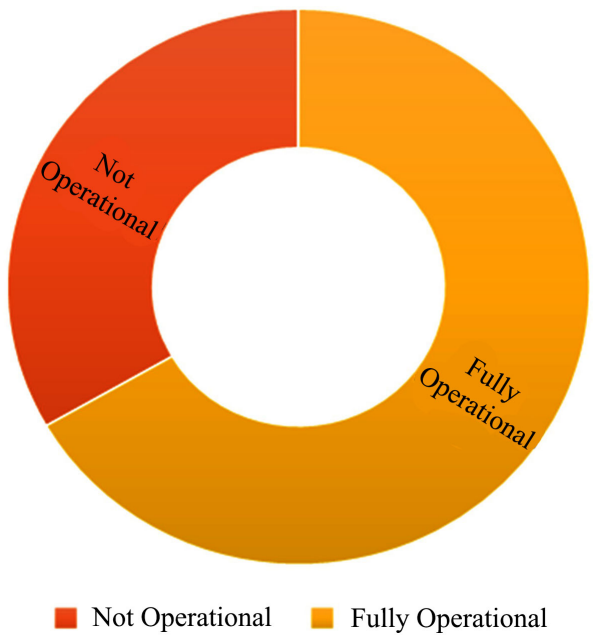

Figure 4. Chart showing results of analysis on the Performance Measurement Structure (Source: Data Analysis).

The result of analysis as shown in Figure 4 showed that organization's process of Performance measurement is fairly strong and operational (67\%). Interestingly, there are specific measures for all or most of the organization's established standards that clearly distinct weak performance from outstanding performance. These measurement criteria are clearly defined, but cannot be quantitatively measured. Relatively, the qualitative measurement cannot interrelate with quantitative results as captured by the employee and thus, it somewhat difficult to equate the outcome with overall agency's mission and public health targets.

There is a strong coordination with the different programs and departments of the agency to avoid duplication of data collection for intended planning and decision making. Data collected using the Performance Appraisal Form but are 
not used as a measure of performance against Agency's target and public health outcome. There is also limited understanding among staff on the performance management criteria and description.

\subsubsection{Performance Reporting of Progress}

Performance reporting is a critical part of the performance management system as its measures how data from performance appraisal is used for purposes other than incentives, reward and promotion but to take significant decisions related to achieving public health outcomes. This section presents findings from the rapid assessment reflecting on the status of the performance reporting process from collection, analysis to use.

The analysis in Figure 5 showed a weak structure for reporting performance which reflected at $62 \%$ gap in the Performance Management System. The Agency has developed a process of documenting its progress related to performance standard and this information is made available to managers, staff and leadership of the organization. The agency has also determined the frequency of collecting performance data, especially around work deliverables, health status, human resource development, financial systems and service delivery.

The most outstanding gaps requiring improvement is that the information documentation does not follow through an established Data and Information Systems and is not used to define client's relationship and satisfaction. The reporting system currently being used does not integrate performance data into new direction for programming, agency's targets, management areas and public health outcome. Staffs of Human Resource are also not trained to effectively analyze and report performance data in relations to meeting Agency's target and contribution to public health outcomes.

\subsubsection{Performance Quality Improvement Process}

This section assesses organization's capacity and process for measuring quality improvement leading to an effective performance management system. The results reflect on which quality improvement structure or process is fully operational or weak.

The findings in Figure 6 reflected that Organization's Quality Improvement Process is very weak, and expected structure not fully operational. There is a designated entity within the organisations that is responsible for monitoring quality of the performance development assessment, but the entity does not have the capacity to conduct quality improvement of the performance management process. There is also not defined timetable or schedule for Performance management quality improvement process; and where it exists is not communicated to staff.

There is a significant gap that information from the performance management process is neither not used to determine areas for more analysis or evaluation, set priorities, allocate/redirect resources as well as informs policy makers of the observed or potential impact of decision under their considerations. There is 


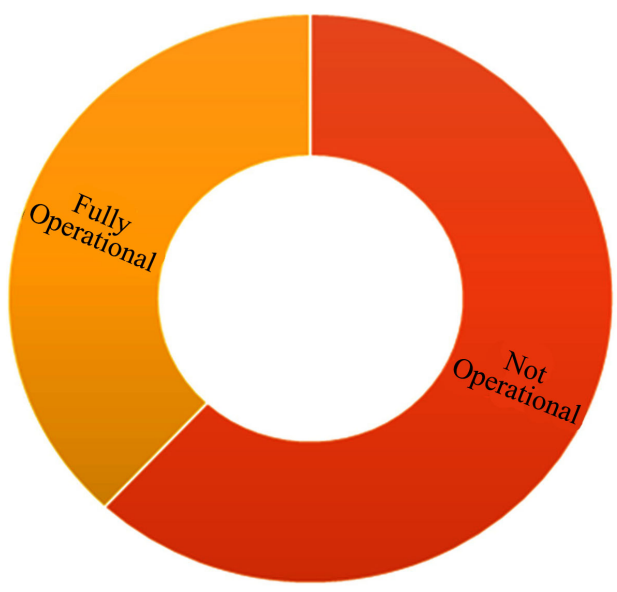

Not Operational Fully Operational

Figure 5. Chart showing results of analysis on the Performance Reporting Rates (Source: Data Analysis).

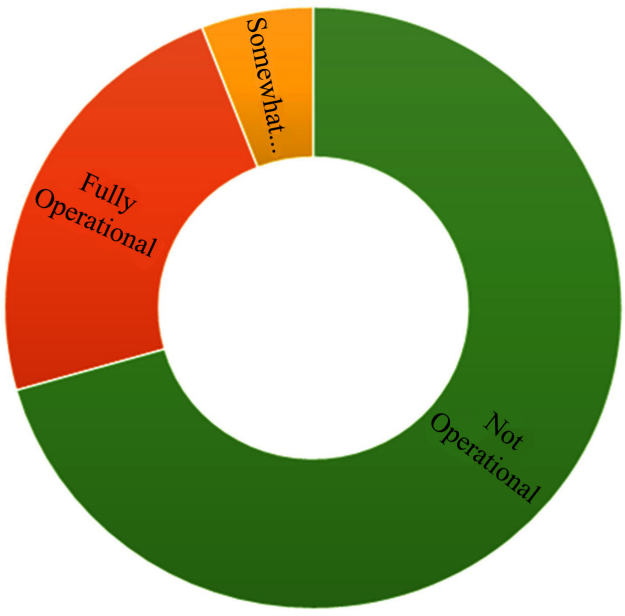

Fully Operational $\quad$ Somewhat Operational $\quad$ Not Operational

Figure 6. Chart showing results of analysis on the Performance Quality Improvement Process (Source: Data Analysis).

also a missing link between the information from the performance management being used to take action managing changes in policies, programs, infrastructure or relationship with clients and stakeholders. The agency is challenged with the capacity to setup, coordinate quality improvement efforts and develop a Quality Improvement plan (with specific timelines, actions and responsible targets) which leads to strengthening performance management system.

\section{Discussion of Findings}

Discussion on performance management contributing to organizational change and work productivity has significantly increased in recent times. Most emphasis has always been on how performance management contributes to employee's productivity, motivation and retention. Little work has been done on linking 
performance management with organization's change and development. This informed the rationale for this assessment to assess how performance management system is structured towards measuring its contributions to organization's target and invariably the public outcome.

Performance management as part of the human resource practice has been linked to improving business or organizational performance [5] [11] [12]. This goes to say that performance management has a way of unveiling the organization's pathway to achieving its set target and establishing evidence for its performance based on the employee's level of contributions. Every organization through its managers is saddled to measure its subordinate's productivity in line with better customer value, organizational knowledge, competency and performance. This validates that a measure of organizational performance has a direct impact on the organization's reputation [13].

Leadership effectiveness and commitment has a significant role to play in measuring organizational performance using the performance management process. The leader's roles include defining standards, executing plans for measuring standards using work effectiveness and efficiency and developing a system that measures how employee's performance contributes to the organizational performance and its public outcomes [14]. Most organizations are challenged with poor innovation, weak performance standards, inability to measure performance standards/targets which affects implementation of the performance management system.

This issue is directly linked to leadership style with lack of strategic direction and intervention towards performance [15]. Somehow, this has a way of affecting or influencing employee's performance. This informs why leadership styles can stimulate or affect performance of employees. It is therefore believed that an organization which requires good reputation should invest in leadership development that directs, motivates, and measures its pathway to performance using its performance management system [16]. The employees also perceived that there is a need of a leader who should not only have to lead people but is also effective, leading the people toward the changes and desired organizational performance and improvement.

This is why performance management is a mechanism that allows organizations direct its employee towards achieving set objectives with direct intent of achieving organization's strategic direction or goals. The process of performance management starts with assessment in most organization. Ideally, organizations should articulate its direction and goal before the commencement of the fiscal year. Some organizations have this direction articulated as strategic operational or annual plan with clearly documented targets and goals. When such direction is communicated, departmental objectives are derived which ideally form the employee's performance objectives. It's expected that during performance appraisal, the employee is measured against its set objectives at his/her level and how such performance is directly linked to the strategic direction of the organization [17]. 
To this end, performance appraisal should not function as a separate or stand-alone system from management or organization's focus. Leaders in the organization merely are conducting a paper chase if its performance appraisal system is not synchronized with the organization's strategic direction and developed in harmony with each staff member's position performance. Several organizations have learned to move from the traditional performance appraisal process that measures only employee's productivity to a conventional approach that links employee's performance to organizational performance mission, vision and goal [18].

Several organizations have also discovered that communicating organization's goals to the arms of the organization and employee clearly help in the alignment of employee's commitment towards achieving the overall goals [19]. In event that this process is not following as stated, it creates an issue of misalignment of employee's performance results with the organization's goals. Without that "clear line in sight" organizations struggle with managing accountability, department and workforce redundancies and general conflicting activities. Relatively, it will create a situation where the employee also lose connection with supporting the organization realized its organization's mission and vision (public health outcome). The resultant effect is that the employees do not understand how they fit into the big picture of organization, as it relates to achieving its public health outcome. The performance management should not be treated as a separate isolated system [20]. Instead, measurement should be considered at the individual, process, and organizational levels but, should be seen to facilitate the achievement of goals of all individuals, teams, departments and processes with the strategic aims of the organization.

In order for organization to achieve the conventional model of performance management, there is need to have a system to capture, document, report and use information from the performance appraisal to measure organization pathway towards meeting their set targets and public health outcomes [21] [22]. This can be achieved through the setting of a functional Human Resource Information System (HRIS) that is built on managing integrating human resource practice inclusive of performance management. The HRIS should strengthen performance reporting starting from communicating priorities of the organization, manages cascade into performance objectives and measuring employee's performance with the organization's target [23].

\section{Conclusions}

This work proposes that conventional approach to performance management helps organization establish a connection with their overall strategic goal and public health outcome. Most organization attends to performance management as a single system with limited understanding on what could be achieved through the performance management process. There is so much emphasis on developing strategic direction annually and conducting performance appraisal 
based on job roles, without building a connection on how the performance of the individual workforce can contribute towards achieving the organization's strategic goals. Such practices will make organization struggle with connecting the performance of their human resource with that of the organization's goal.

The outcome of this work further revealed a gap in the current practice of performance management in relation to linking performance data to the overall organizational performance and public health outcome. The study affirms a missing link created by implementing a traditional performance management system that only focuses on reward and promotion as incentives to performance outcome. It could be seen that there is need to improve on the current traditional practice to ensure a system and process is instituted to capture, analyze and connect performance outcome with strategic focus and goal of the organisation.

A key gap identified in this work focused on leadership commitment and capacity to drive a human resource system that connects performance management to strategic goals. The outcome of the work revealed that leaders pay attention to set strategic direction without considering that these strategic goals are implemented by the workforce. What process is then instituted to back trace how the individual effort of the staff links with the strategic goals? This can be achieved if the leadership is committed and possess the needed capacity to use performance data to equate their strategic goals which is in this case is the public health outcome.

Although the leadership of the organization is expected to lead the process of the conventional performance management practice, it should also consider the capacity of its human resource team to implement this model. Traditional human resource team pays attention to facilitate the process of performance discussion, mentorship and appraisal within the stipulated timelines in the human resource policy. The study revealed that data are collected using appropriate form but lack the capacity to analyze and interpret such data to guide management and leadership decision towards the overall strategic goal and public health outcomes. It is then necessary for leadership of organization interested in this conventional performance management approach to invest in its human resource team to perform this function effectively, not separately but as part of the human resource management practices.

This work also recognizes the importance of performance standards in assisting organization to measure employee's contributions towards the achievement of the organizational goals. Performance standards developed and utilized for performance appraisal are most times related to achievement of job roles, but not necessarily helping the employee to measure its contributions to the overall strategic goal and public health outcome. Achieving this would require an alignment of performance standards with the management standards as captured in the strategic direction. This effort further makes employees to be conscious of the fact that their productivity is not only measured by completion of job roles but how those performance results adds-up to the achievement of the organization's goals. 
In conclusion, it is important to mention that performance management is more than just a process for rewarding employee's productivity. Performance management should be used as a tool or process for the organization to collect data to help them measure their overall performance based on its employee's efforts. Organizations can maintain their reputation when data from the performance management process are used to inform organizational change, policy review and accountability to the stakeholders.

\section{Acknowledgements}

The author acknowledges the support of Dr. Marketa Hinkova of LIGS University for providing the initial guidance.

\section{Conflicts of Interest}

The author declares no conflicts of interest regarding the publication of this paper.

\section{References}

[1] Graver, K. and Austin, S. (1995) Additional Evidence on Bonus Plans and Income Management. Journal of Accounting and Economics, 19, 3-28. https://doi.org/10.1016/0165-4101(94)00358-C

[2] Ceriello, V. and Freeman, C. (1991) Human Resource Management Systems: Strategies, Tactics, and Techniques. Lexington Books, Lexington, MA.

[3] Roberts, G.E. and Reed, T. (1996) Performance Appraisal Participation, Goal Setting and Feedback. Review of Public Personnel Administration, 16, 29-60.

[4] Grote, R. (2005) Forced Ranking: Making Performance Management Work. Harvard Business School Press, Boston, MA.

[5] Smither, J.W. (1998) Performance Appraisals: A State of the Art in Practice. Josey-Bass, San Francisco, 132-162.

[6] Kane, J.S. and Lawler, E.E. (2009) Performance Appraisal Effectiveness: Its Assessment and Determinants. Research in Organizational Behavior, 1, 425-478.

[7] Meyer, H.H. (1991) A Solution to the Performance Appraisal Feedback Enigma. Academy of Management Executive, 5, 68-76.

[8] Longenecker, C.O. (1988) Neglected at the Top: Executives Talk about Executive Appraisal. MIT Sloan Management Review, 29, 41-47.

[9] Levy, P.E. and Williams, J.R. (2004) The Social Context of Performance Appraisal: A Review and Framework for the Future. Journal of Management, 30, 881-905. https://doi.org/10.1016/j.jm.2004.06.005

[10] Fletcher, C. (2004) Appraisal and Feedback: Making Performance Review Work. 3rd Edition, Chartered Institute of Personnel and Development, London.

[11] Scott, S.G. and Einstein, W.O. (2001) Strategic Performance Appraisal in Team-Based Organizations: One Size Does Not Fit All. Academy of Management Executive, 15, 107-116. https://doi.org/10.5465/ame.2001.4614990

[12] Mallaiah, T.Y. (2009) Management of Employee Expectations, Performance and Satisfaction in University Library: An Empirical Study. Annals of Library and Information Studies, 56, 7-12. 
[13] Klimoski, R. and Inks, L. (1990) Accountability Forces in Performance Appraisal. Organizational Behavior and Human Decision Processes, 45, 194-208. https://doi.org/10.1016/0749-5978(90)90011-W

[14] Northouse, P.G. (2001) Leadership: Theory and Practice. Sage Publication, Inc., London.

[15] Doran, G.T. (1981) There's a S.M.A.R.T. Way to Write Management's Goals and Objectives. Management Review, 70, 35-36.

[16] Javadin, S.R. (2001) Human Resources Management. Tehran Negahe Danesh Publication, Tehran, Iran.

[17] Greengard, S. (1997) Extranets: Linking Employees with Your Vendors. Workforce, 76, 28-34.

[18] Waggoner, D. (1999) The Forces that Shape Organizational Change. Kogan Page, London.

[19] Larson, J.R. (1989) The Dynamic Interplay between Employees' Feedback-Seeking Strategies and Supervisors' Delivery of Performance Feedback. The Academy of Management Review, 14, 408-422. https://doi.org/10.5465/amr.1989.4279075

[20] Cederblom, D. (1982) The Performance Appraisal Interview: A Review, Implications and Suggestions. The Academy of Management Review, 7, 219-227. https://doi.org/10.5465/amr.1982.4285572

[21] Birkhead, G.S., Klopmas, M. and Shah, N.R. (2015) Uses of Electronic Health Records for Public Health Surveillance to Advance Public Health. Annual Review Public Health, 36, 345-359.

[22] Walker, A. (1993) Handbook of Human Resource Information Systems: Reshaping the Human Resource Function with Technology. McGraw-Hill, New York.

[23] Waldersee, R. and Luthans, F. (1994) The Impact of Positive and Corrective Feedback on Customer Service Performance. Journal of Organizational Behavior, 15, 83-95. 